\title{
Effect of season on seminal traits and serum hormone concentrations in captive male Siberian tigers (Panthera tigris)
}

\author{
A. P. Byers*, A. G. Hunter*, U. S. Seal $\dagger$, E. F. Graham* and R. L. Tilson $\ddagger$ \\ *Department of Animal Science, University of Minnesota, St Paul, MN 55108, USA; \\ $\dagger$ V.A. Medical Center, Minneapolis, MN 55417, USA; and $\$$ Minnesota Zoological Garden, \\ Apple Valley, MN 55124, USA
}

\begin{abstract}
Summary. Electroejaculates and serum samples were collected throughout the year from 5 male Siberian tigers. Semen quality, seminal plasma chemistry and serum hormone concentrations were evaluated and analysed as a function of season. Semen volume, concentration, motility, viability and morphology were not influenced by season. The ability of spermatozoa to undergo capacitation and penetrate zona-free hamster eggs did not differ due to season. Season had no influence on seminal plasma concentrations of acid phosphatase, calcium, glucose, potassium and phosphorus. Serum values of thyroxine and triiodothyronine were lowest $(P=0.002$ and $P=0.03$, respectively) during the summer months while cortisol showed no seasonal variation. Serum testosterone concentrations were higher in fall and early winter $(P<0.001)$ than at other times of the year but were not correlated with semen quality. These results demonstrate that season has no effect on the semen production and quality of captive male Siberian tigers.
\end{abstract}

Keywords: seasonality; Siberian tiger; semen quality; captive breeding

\section{Introduction}

The Siberian tiger is an endangered species, the continued existence of which has become the responsibility of captive management programmes (Seal \& Foose, 1983). To manipulate the reproduction of this species successfully it is essential that we understand its reproductive physiology. This includes the question of whether or not the tiger's reproductive capacity is altered due to environmental changes throughout the year.

An analysis of birth records of captive tigers in the northern hemisphere showed that the majority of births occurred in the months of April, May and June (ISIS, 1983; Seifert \& Muller, 1985). Allowing for a gestation period of approximately 105 days (Sadleir, 1966), it was apparent that the majority of matings took place between January and March. From a study of the endocrine profiles of female Siberian tigers, Seal et al. (1985) concluded that the female tiger is a polyoestrous seasonal breeder, with reproductive activity being under the influence of photoperiod. In the northern hemisphere the breeding season begins in late January and lasts until early June.

Although the reproductive cycle in the female of a species may be seasonal, the male of that species does not necessarily show seasonal variations in sperm production and semen quality. The reproductive activity of the female clouded leopard is seasonal, while the male experiences no seasonal effects on semen quality when analysed on a quarterly basis (Wildt et al., 1986b). The objective of our study was to determine whether season affects the semen production and quality of the male tiger, Panthera tigris, and should therefore be taken into account when planning research and breeding strategies. 


\section{Materials and Methods}

Animals and semen collection. Five Siberian tigers (Panthera tigris), described by Byers et al. (1989), were used for this study. They ranged in age from 2 to 14 years. The 3 animals from the Minnesota Zoological Garden (Apple Valley, MN, USA) were proven sires, while the 2 from the Como Zoo (St Paul, MN) were young and had not been used in a breeding programme. All the animals were housed separately with free access to the outside, and natural photoperiod, throughout the year. They were fed a prepared carnivore diet (Nebraska brand Feline Diet) and water was available ad libitum.

The animals were anaesthetized using approximately $700 \mathrm{mg}$ ketamine, $80 \mathrm{mg}$ zylazine and $20 \mathrm{mg}$ diazepam, administered by blow-dart. Additional ketamine was used as needed to maintain anaesthesia. A standardized electroejaculation protocol (Byers et al., 1989) was used to collect the semen. Semen was collected from each animal on a weekly or bi-weekly basis. However, not all samples were made available for this study due to other demands.

Spermatozoa and seminal plasma analysis. The semen was transported to the laboratory at $37^{\circ} \mathrm{C}$ where semen volume, sperm concentration, motility, viability and morphology were evaluated (Byers et al., 1989). A fraction of the sperm sample was capacitated in vitro according to the procedure of Byers et al. (1989) and used in the hamster egg sperm-penetration assay (Byers et al., 1987). The remainder of the sample was centrifuged three times at $800 \mathrm{~g}$ to separate the spermatozoa from the seminal plasma. The seminal plasma was frozen at $-20^{\circ} \mathrm{C}$ until its chemical components were analysed. Potassium, phosphorus, calcium and glucose were measured on an ASTRA system (Automated Stat Routine Analyzer, Beckman Instruments, Brea, CA). A Gemstar Analyzer (Electro-Nucleonics, Fairfield, $\mathrm{NJ}$ ) was used to measure acid phosphatase.

Serum collection and hormone assays. On each collection day, one blood sample/animal was taken $30-40 \mathrm{~min}$ after the first injection of immobilizing drugs, and before electroejaculation. The blood was allowed to clot and the serum drawn off and frozen at $-20^{\circ} \mathrm{C}$ until used in radioimmunoassays for measurement of testosterone, cortisol, thyroxine and triiodothyronine.

Testosterone samples were extracted from serum using diethyl ether and quantitated by radioimmunoassay as described by McMillin et al. (1974). The sensitivity was $50 \mathrm{pg}$ ( $1 \mathrm{ml}$ of sample was used in the assay providing a sensitivity of $50 \mathrm{pg} / \mathrm{ml}$ ) and a CV of $15 \%$ at $50 \mathrm{pg}$.

Cortisol was determined by competitive protein binding radioimmunoassay as described by Kreeger et al. (1990) using commercial cortisol standards (Calbiochem-Behring, San Diego, CA, USA). Sensitivity was $1.0 \mu \mathrm{g} / \mathrm{dl}$ and inter-assay CV was $12 \cdot 8 \%$.

Thyroxine $\left(\mathrm{T}_{4}\right)$ and triiodothyronine $\left(\mathrm{T}_{3}\right)$ were determined by solid-phase radioimmunoassay (Diagnostic Products Corp., Los Angeles, CA, USA) as described by Kreeger et al. (1990). The assays were highly specific with no significant cross-reactivity with any other compounds. Sensitivity for $\mathrm{T}_{4}$ was $0.5 \mu \mathrm{g} / \mathrm{dl}$ and for $\mathrm{T}_{3}$ was $7.0 \mathrm{ng} / \mathrm{dl}$. Intraassay and inter-assay $\mathrm{CV}$ for $\mathrm{T}_{4}$ were $11 \cdot 3$ and $18.2 \%$ respectively. Intra-assay and inter-assay $\mathrm{CV}$ for $\mathrm{T}_{3}$ were $10 \cdot 6$ and $13 \cdot 2 \%$ respectively.

Statistics. For analysis by season, the year was divided into four quarters, namely winter (December, January, February), spring (March, April, May), summer (June, July, August) and fall (September, October, November). An average of $41 \cdot 7$ ejaculates were analysed/parameter studied. This averaged $10 \cdot 2$ ejaculates/season and $2 \cdot 1$ ejaculates/ season/tiger.

Data were analysed using a two-way analysis of variance for unbalanced data (Snedecor \& Cochran, 1967; Stat View 512 + Software [Brain Power, Inc., Calabasas, CA 91302, USA]) because sample sizes/season were unequal.

\section{Results}

The mean \pm s.d. total sperm concentration was $57.0 \pm 54.6 \times 10^{6}$ spermatozoa with an average ejaculate volume of $10 \cdot 3 \pm 3.9 \mathrm{ml}$ (Figs 1a, b). Neither of these semen characteristics varied with season $(P>0.05)$.

No seasonal variation $(P>0.05)$ was detected in the seminal parameters of $\%$ normal morphology, \% viability (Figs 1c, d) or \% progressive motility (Fig. le). These seminal parameters per ejaculate averaged $59 \cdot 3 \pm 15 \cdot 5 \%$ motile cells, $57 \cdot 4 \pm 14 \cdot 6 \%$ live cells and $78 \cdot 3 \pm 10 \cdot 3 \%$ cells with normal morphology. The abnormal cells $(21.9 \%)$ consisted of cells with a coiled flagellum $(9.0 \%)$, bent neck $(8.9 \%)$, bent flagellum $(2.7 \%)$, cytoplasmic droplets $(1.0 \%)$ or macro/microcephalic $(0.3 \%)$. No significant difference due to season was detected for any of these abnormalities.

The ability of tiger spermatozoa to undergo capacitation and penetrate zona-free hamster eggs is presented in Fig. 1 (f). The percentage of eggs penetrated by tiger spermatozoa in each season did not differ $(P>0.05)$. The overall penetration rate was $18.2 \pm 9 \cdot 5 \%$. 

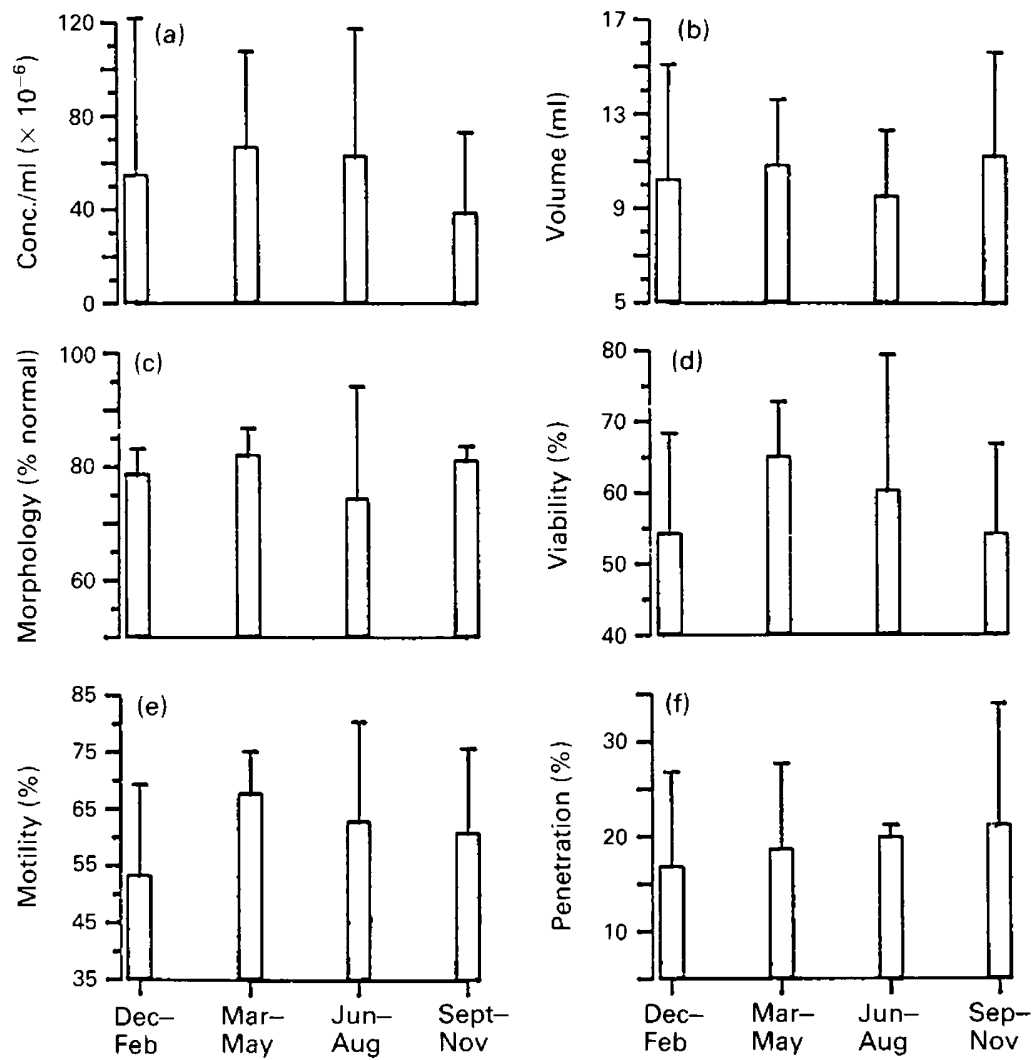

Fig. 1. Seasonal sperm and semen values for 5 male Siberian tigers. (a) Sperm concentration, $n=49$, (b) semen volume, $n=46$, (c) $\%$ normal morphology, $n=38$, (d) $\%$ viability, $n=40$, (e) $\%$ progressive sperm motility, $n=45$, and (f) $\%$ penetration of zona-free hamster eggs, $n=24$. Values are mean \pm s.d.

The seminal plasma concentrations of phosphorus, calcium, acid phosphatase, glucose and potassium were $2.4 \pm 1.0 \mathrm{mg} / \mathrm{dl}, \quad 4.5 \pm 0.09 \mathrm{mg} / \mathrm{dl}, \quad 5.6 \pm 2.1 \mathrm{IU} / \mathrm{l}, \quad 2.4 \pm 1.2 \mathrm{mg} / \mathrm{dl}, \quad$ and $13.6 \pm 1.3$ mequiv./l, respectively. These seminal constituents (Fig. 2) showed no seasonal variations $(P>0.05)$.

The overall serum concentrations of thyroxine and triiodothyronine were $1 \cdot 7 \pm 0.7 \mu \mathrm{g} / \mathrm{dl}$ and $62 \cdot 8 \pm 20 \cdot 1 \mathrm{ng} / \mathrm{dl}$. The concentrations of the thyroid hormones changed with season (thyroxine: $P=0.002$; triiodothyronine: $P=0.03$ ) (Figs 3a, b). Particularly, thyroxine values were significantly lower in the summer months of June, July and August.

The concentration of serum testosterone was $278.2 \pm 155.8 \mathrm{ng} / \mathrm{dl}$ over the four seasons. Testosterone concentrations did vary with season $(P<0.001)$ (Fig. 3c). Values in the fall and early winter were significantly higher than in the spring and summer months.

The concentration of serum cortisol was $11.6 \pm 3.8 \mu \mathrm{g} / \mathrm{dl}$ over the four seasons. Cortisol was measured as an indicator of adrenal function and stress (Fig. 3d) and no seasonal variations were seen $(P>0.05)$.

\section{Discussion}

The results of the semen analyses reported here are within the range reported previously by us (Byers et al., 1989) and others (Wildt et al., 1987). No seasonal variations were found for the 

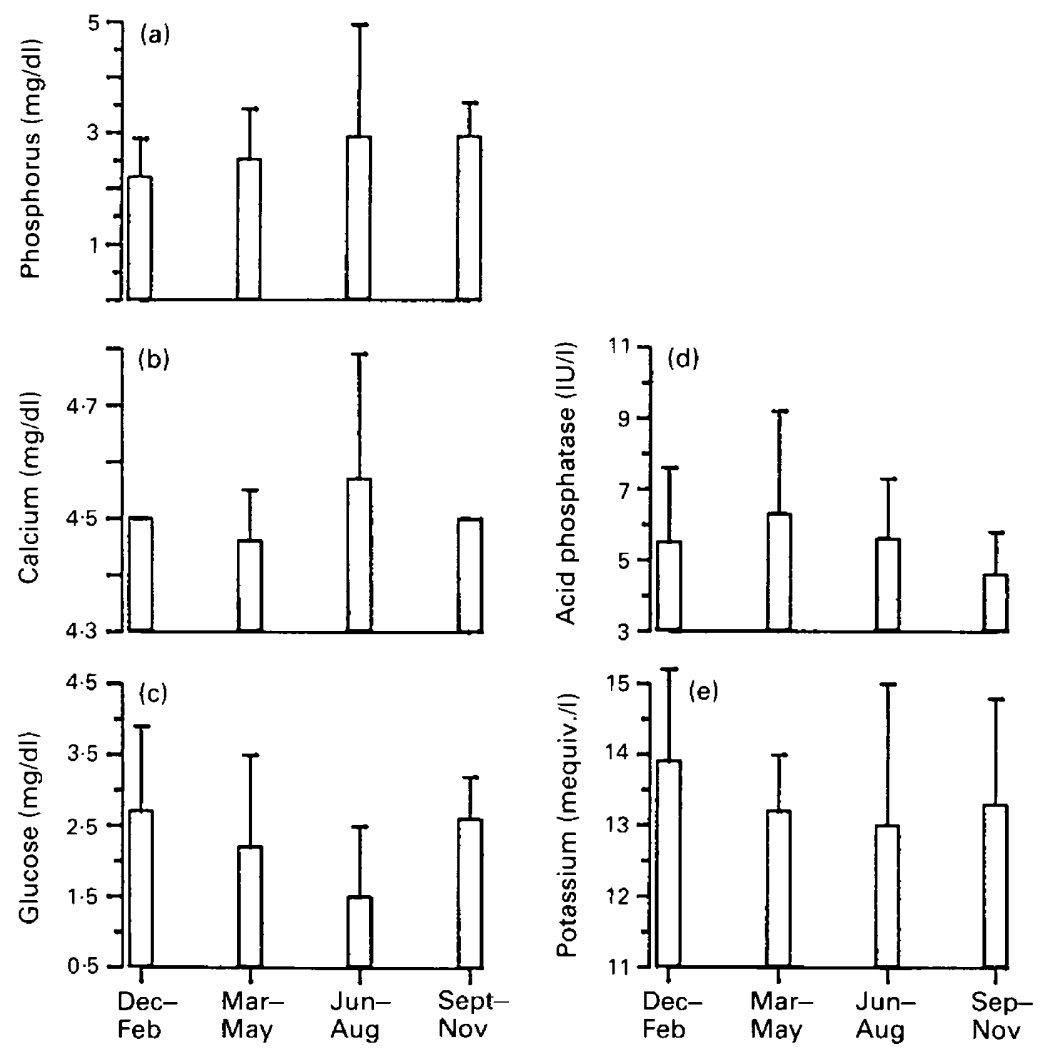

Fig. 2. Seasonal seminal plasma concentrations of (a) phosphorus, (b) calcium, (c) glucose, (d) acid phosphatase and (e) potassium in 5 male Siberian tigers. Samples were evaluated 26 times during the year. Values are means \pm s.d.
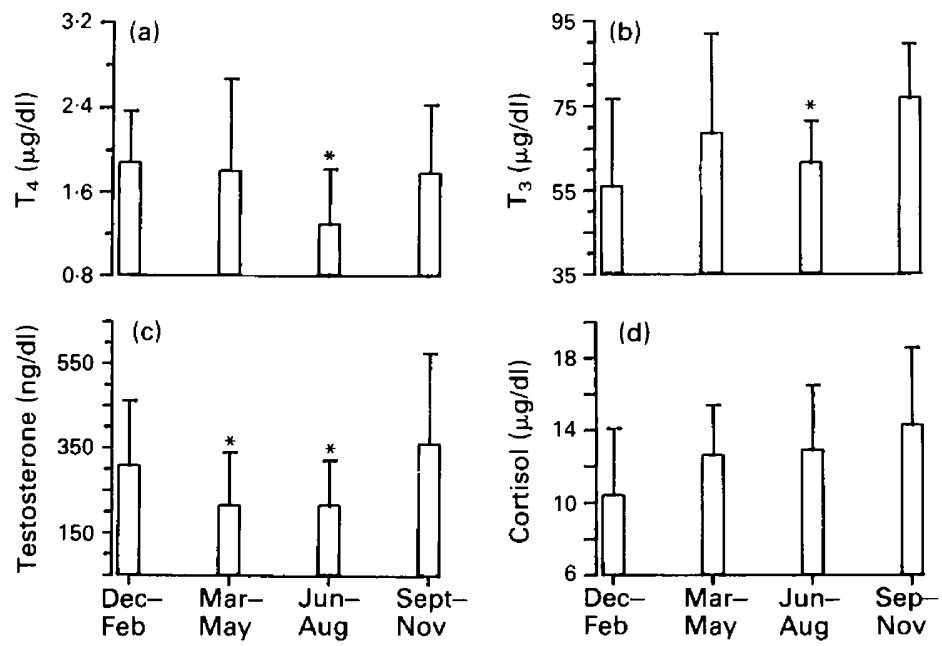

Fig. 3. Seasonal blood serum concentrations of (a) thyroxine, $n=52$, (b) triiodothyronine, $n=52$ (c) testosterone, $n=77$, and (d) cortisol, $n=72$, in 5 male Siberian tigers. Values are means \pm s.d. *Significantly different, $P<0.05$. 
functional characteristics of semen volume, sperm concentration, motility, viability and morphology. These parameters make up the routine semen analysis which is used as the first step in any evaluation of male fertility. Normal values for many species, including the tiger (Wildt et al., 1987, 1988; Byers et al., 1989), have been established and individuals with abnormal levels in one or more parameter are considered to be of questionable fertility (Rogers, 1985). The consistent tiger semen analysis results obtained throughout the period of this study support the conclusion that the male tiger's reproductive capability does not vary with season. Similarly, when semen quality of the clouded leopard was analysed by season (Wildt et al., 1986b), no differences were seen. This is in contrast to the reproductive seasonality seen in the female clouded leopard which is in oestrus primarily only from late December to early February (Wildt et al., 1986b).

Season had no influence on the ability of tiger spermatozoa to undergo capacitation and penetrate zona-free hamster oocytes. The mean penetration rate of $18 \%$ is in line with results reported by Byers et al. $(1987,1989)$. Successful penetration of intact oocytes requires the completion of a sequence of sperm functions including capacitation, zona-binding, the acrosome reaction and appropriate movements of the sperm tail (Yanagimachi, 1981). Completion of capacitation, the acrosome reaction and sperm binding to the oocyte plasma membrane are required for sperm penetration of zona-free hamster oocytes (Yanagimachi, 1984). The hamster egg-sperm penetration assay is the best available test of sperm functionality in species for which the use of homologous oocytes is not possible (Rogers, 1985). In addition, this test provides information on tiger spermatozoa that is not provided by semen analysis (Byers et al., 1989).

Several factors can potentially influence seminal chemistry including frequency of collection, method of semen collection, semen handling and season (Graham et al., 1970). All samples used in this study were collected under similar conditions, essentially ruling out the effect of collection and handling variables. No seasonal effect was observed in the seminal plasma concentrations of acid phosphatase, calcium, potassium, phosphorus, and glucose in tigers. These constituents were chosen for evaluation because, in the bull, potassium $(P<0.05)$, phosphorus $(P<0.01)$ and acid phosphatase $(P<0.05)$ were positively correlated to fertility while calcium $(P<0.01)$ and glucose $(P<0.01)$ were negatively correlated to fertility (Graham et al., 1970).

Serum cortisol concentrations did not differ due to season and the annual mean cortisol values are similar to those reported by other investigators (Seal et al., 1978; Wildt et al., 1987, 1988). In addition to illustrating the lack of seasonal influence on serum cortisol levels $(P>0.05)$ these results indicate that these animals were not increasingly stressed by the repeated immobilizations performed throughout the year. For example, the cortisol values over time for a representative male were $14.2 \pm 2 \cdot 6,13.0 \pm 3 \cdot 3,12.9 \pm 3.6$ and $13.2 \pm 5 \cdot 1 \mu \mathrm{g} / \mathrm{dl}$ for winter, spring, summer and fall, respectively. Although Wildt et al. (1986a) reported gradually increasing concentrations of cortisol over time in the clouded leopard, they suspect that this was related to psychogenic responses to repeated manipulations rather than seasonal influences.

Seasonal variations were seen in serum concentrations of the thyroid hormones, particularly thyroxine. The high levels of thyroxine observed during the winter suggest a normal increase in thyroid activity in response to cold. These results give us confidence that the metabolic function in these animals was normal throughout the course of this study.

Circulating testosterone values also varied due to season. The annual mean testosterone concentrations reported here are similar to those found by Wildt et al. $(1987,1988)$. The rise in testosterone concentrations in the male a few months before the onset of oestrus in the female is not an unusual occurrence. This is seen in other wild species including deer. The doe is reproductively active from November until early March (Plotka et al., 1977) while, in the male, testosterone concentrations begin to rise in August, with peak levels in October (McMillin et al., 1974). In the clouded leopard, testosterone values were greater $(P<0.05)$ in winter than in any other season (Wildt et al., 1986a).

While the seasonal differences in testosterone concentrations in tigers were statistically significant they did not affect changes in semen quality. This agrees with a previous report that testoster- 
one values in the tiger were not correlated $(P>0.05)$ to any ejaculate characteristics including sperm concentration, motility and morphology (Wildt et al., 1987). The same is true in the clouded leopard (Wildt et al., 1986a) and Dorcas gazelle (Howard et al., 1983).

In addition, our testosterone results indicate that photoperiod, which is believed to be the impetus for the increase in reproductive activity in the female tiger (Seal et al., 1985), is not responsible for the changes in this reproductive hormone in the male. There are several environmental stimuli reported to result in changes in testosterone concentrations. Nutrition may affect serum testosterone values (Grewal et al., 1971), but the animals in this study were all fed the same diets and maintained their average body weight throughout the year. Exposure to receptive females has been shown to increase circulating testosterone concentrations in rhesus monkeys (Rose et al., 1972), but since testosterone in the male tigers increased several months before the breeding season of the females it is unlikely that this is an important hormonal influence. The changes observed in this study may be due to the functioning of an innate cirannual rhythm or the response of the male to an extremely subtle cue from the environment. More frequent sampling would be required to identify the frequency and timing of these changes in hormone concentrations.

Individual variations in most of the characteristics we examined were large and work with a species such as the tiger limits the number of samples that can be collected. Nevertheless, our data overwhelmingly indicate that semen production and quality are not affected by changes in season. Therefore, we conclude that season has no apparent effect on the functional reproductive ability of captive male Siberian tigers, and that semen collected throughout the year can be used for research and breeding purposes.

Financial support was provided by the Minnesota Zoological Garden, the Veteran's Administration Research Service and the University of Minnesota Agricultural Experiment Station Project 72.

We thank M. F. Seal, G. A. Binczik and Steve Wickstrom for statistical assistance; and Mary D. Lewis, Nancy Manning and Sue Ruen, technicians from Dr U. S. Seal's laboratory at the Veterans Administration Hospital.

\section{References}

Byers, A.P., Hunter, A.G., Hensleigh, H.C., Kreeger, T.J., Binczik, G., Reindl, N.J., Seal, U.S. \& Tilson, R.L. (1987) In vitro capacitation of Siberian tiger spermatozoa. Zoo Biol. 6, 297-304.

Byers, A.P., Hunter, A.G., Seal, U.S., Binczik, G.A., Graham, E.F., Reindl, N.J. \& Tilson, R. (1989) Invitro induction of capacitation of fresh and frozen spermatozoa of the Siberian tiger (Panthera tigris). $J$. Reprod. Fert. 86, 588-607.

Graham, E.F., Schmehl, M.K. \& Maki-Laurila, M. (1970) Some physical and chemical methods of evaluating semen. 3rd Tech. Conf. Anim. Reprod, and A.I., $N A A B$, Chicago, pp. $2-6$.

Grewal, T., Mickelsen, O. \& Hafs, H.D. (1971) Androgen secretion and spermatogenesis in rats following semistarvation. Proc. Soc. exp. Biol. Med. 138, 723-727.

Howard, J.G., Wildt, D.E., Chakraborty, P.K. \& Bush, M. (1983) Reproductive traits including seasonal observations on semen quality and serum hormone concentrations in the Dorcas gazelle. Theriogenology 20, 221-233.

International Species Inventory System (ISIS). (1983) Species Distribution Report. ISIS, Apple Valley, MN.
Kreeger, T.J., White, P.J., Seal, U.S. \& Tester, J.R. (1990) Pathological responses of red foxes to foothold traps. J. Wildl. Mgmt 54, 147-160.

McMillin, J.M., Seal, U.S., Keenlyne, K.D., Erickson, A.W. \& Jones, J.E. (1974) Annual testosterone rhythm in the adult white tailed deer (Odocoileus virginianus borealis). Endocrinology 94, 1034-1040.

Plotka, E.D., Seal, U.S., Schmoller, G.C., Karns, P.D. \& Keenlyne, K.D. (1977) Reproductive steroids in the White-tailed deer (Odocoileus virginianus borealis). I. Seasonal changes in the female. Biol. Reprod. 16, 340-343.

Rogers, B.J. (1985) The sperm penetration assay: its usefulness reevaluated. Fert. Steril. 43, 821-839.

Rose, R.M., Gordon, T.P. \& Bernstein, I.S. (1972) Plasma testosterone levels in the male Rhesus: influences of sexual and social stimuli. Science, $N Y$ 178, 643-645.

Sadleir, R.M.F.S. (1966) Notes on reproduction in the larger felidae. Int. Zoo Yearbook 6, 184-187.

Seal, U.S. \& Foose, T. (1983) Species survival plan for Siberian tigers in North American zoos: a strategy for survival. Proc. Am. Assoc. Zoo Veterinarians, Tampa, pp. 3340 . 
Seal, U.S., Plotka, E.D. \& Gray, C.W. (1978) Baseline hematology, serum chemistry and hormone data for captive tigers (Panthera tigris ssp) and lions (Panthera leo). In International Tiger Studbook, pp. 174-192. Zoologischer Garten Leipzig, Leipzig.

Seal, U.S., Plotka, E.D., Smith, J.D., Wright, F.H., Reindl, N.J., Taylor, R.S. \& Seal, M.F. (1985) Immunoreactive luteinizing hormone, estradiol, progesterone, testosterone and androstenedione levels during the breeding season and anestrus in Siberian tigers. Biol. Reprod. 32, 361-368.

Seifert, S. \& Muller, P. (1985) International Tiger Studbook. Zoologischer Garten Leipzig, Leipzig.

Snedecor, G.W. \& Cochran, W.G. (1967) Statistical Methods, 6th edn. Iowa State University Press, Ames.

Wildt, D.E., Howard, J.G., Chakraborty, P.K. \& Bush, M. (1986a) Reproductive physiology of the clouded leopard. II. A circannual analysis of adrenalpituitary-testicular relationships during electroejaculation or after an adenocorticotropin hormone challenge. Biol. Reprod. 34, 949-959.

Wildt, D.E., Howard, J.G., Hall, L.L. \& Bush, M. (1986b) Reproductive physiology of the clouded leopard. I. Electroejaculates contain high pro- portions of pleiomorphic spermatozoa throughout the year. Biol. Reprod. 34, 937-947.

Wildt, D.E., Phillips, L.G., Simmons, L.G., Goodrowe, K.L., Howard, J.G., Brown, J.L. \& Bush, M. (1987) Seminal-endocrine characteristics of the tiger and the potential for artifical breeding. In Tigers of the World; The Biology, Biopolitics, Management and Conservation of an Endangered Species, pp. 255-279. Eds R. L. Tilson \& U. S. Seal. Noyes Publications, New Jersey.

Wildt, D.E., Phillips, L.G., Simmons, L.G., Chakraborty, P.K., Brown, J.L., Howard, J.G., Teare, A. \& Bush, M. (1988) A comparative analysis of ejaculate and hormonal characteristics of the captive male cheetah, tiger, leopard and puma. Biol. Reprod. 38, 245-255.

Yanagimachi, R. (1981) Mechanisms of fertilization in mammals. In Fertilization and Embryonic Development In Vitro, pp. 81-182. Eds L. Mastroianni, Jr \& J. D. Biggers. Plenum Publishing, New York.

Yanagimachi, R. (1984) Zona-free hamster eggs: their use in assessing fertilizing capacity and examining chromosomes of human spermatozoa. Gamete Res. 10, 187-232.

Received 14 November 1989 